\title{
Perinatal Subependymal Hemorrhage
}

National Cancer Institute

\section{Source}

National Cancer Institute. Perinatal Subependymal Hemorrhage. NCI Thesaurus. Code C117201.

Bleeding into the thick layer of immature cells under the ependymal lining at the ventrolateral aspect of the lateral cerebral ventricles occurring around the time of birth. 